\title{
THE DETERRENT EFFECTS OF BRAZILIAN CHILD LABOR LAWS
}

\author{
Cristiano Aguiar de Oliveira ${ }^{7}$
}

Gabriel Costeira Machado²

\section{Keywords}

law / child labor / quasi-experiment / regression discontinuity

\section{SUMMARY}

\section{Introduction. 2. Brazilian child labor law. 3. Identification Strategy. 3.1. Data. 3.2. Methodology. 4. Results. 5. Final}

\section{Considerations. 6. References.}

1 Professor of the Graduate Program in Applied Economics at the Federal University of Rio Grande (PPGE/FURG).

2 PhD student of the Graduate Program in Applied Economics at Luiz de Queiroz College of Agriculture - University of São Paulo (ESALQ/USP).

\section{Abstract}

Brazilian law prohibits all forms of work for children under the age of 14 years old. Therefore, work performed by children under 14 years of age is subject to sanctions that do not apply to work performed by those over 14 years of age. We use this quasi-experiment generated by Brazilian law to test the deterrent effects of such sanctions. For this purpose, we use the 2013 National Household Sample Survey (Pesquisa Nacional de Amostra por Domicílios - PNAD) data to estimate the local average treatment effects (LATE) using the regression discontinuity approach. The results indicate that on average, this law results in $88 \%$ fewer weekly working hours when individuals living in rural and urban areas are considered. The effects in rural areas are thus inconclusive. The paper concludes that the law has a deterrent effect and reduces child labor in Brazil, but the effects are ambiguous in rural areas, where law enforcement is weaker, and more children work. 


\section{INTRODUCTION}

Analyzing the deterrent effects of any law is a difficult task due to the complexity of the mechanism in itself. Laws can make an article illegal (e.g., weapons), increase the harshness of a punishment (e.g., the death penalty), or alter the manner in which the punishment is administered ("threestrikes laws"), for example. A law, even if it is relevant, is merely one element within the set of elements that agents consider in their decision-making. Many laws end up having an effect opposite to that intended by their proponents because they generally ignore other factors, such as the reactions of the agents toward the new institutional framework and the chain of consequences that arises with new rules. In other words, often, only the impacts on the partial equilibrium are considered, and the general equilibrium is ignored. Empirical researchers seeking to identify the global effects of a law face many challenges that unfortunately cannot be overcome.

A recurrent empirical challenge is developing methods to control the other elements that affect decisions, considering that information about these may be unavailable or non-existent. This omission of relevant independent variables is always a source of worry for researchers who attempt to obtain non-biased estimators of the impacts of institutional changes. This problem can partially be overcome via the use of panel data because such data enable controlling this un-observed heterogeneity through estimations that exclude fixed effects, i.e., characteristics of the unit analysis that do not change with time. However, this problem is not the only one to be solved. To identify the deterrent effects of a law, a counterfactual analysis is necessary; i.e., it is necessary to determine what violations would occur if such a law did not exist.

It is not always easy to obtain this counterfactual scenario.3 The most common strategy is to divide the units into two groups (treated and control). The treated group represents those units under the new law, whereas the control refers to those units subject to no change in the law. This process is facilitated when there are differences in legislation between states, such as in the USA. In Brazil, this task is more difficult because criminal laws are applied throughout the whole national territory, although they are applied by independent justice systems.4 Therefore, it is impossible to determine the deterrent effect of a law through regional variations, and it is only possible to evaluate the various efforts in applying it, i.e., regional differences in the likelihood of the punishment resulting from the local justice system's efficiency.

However, the use of panel data is not a definitive solution for the problems caused by endogeneity because simultaneity problems and measurement errors in the independent variables included in the empirical models will continue to hamper causality inferences. The use of instrumental variables, although very common, is far from being a solution to the violation of the strict exogeneity condition, which is necessary to obtain non-biased estimates. It is very complicated to obtain exogenous variations capable of identifying a model of simultaneous equations and, as consequence, to have a model immune to criticism.

${ }^{3}$ A recently proposed strategy that has become increasingly popular is the synthetic control technique proposed by Abadie and Gardeazabal (2003), which enables construction of a counterfactual vector from the time series of other geographic units to be compared with the time series of a certain region.

Each state has its own police, prosecutor (public ministry) and judiciary. 
Methodological criticism and arguments without a definitive conclusion can be observed in several attempts to assess the deterrent effects of laws. These are the cases of "three-strikes laws" (lyengar, 2008; Shepherd, 2002; Marvell \& Moody, 2001), the death penalty (Berk, 2005; Fagan, 2006; Zimring, 2008; Cohen-Cole et al., 2009; Dezhbakhsh et al., 2003; Donohue \& Wolfers, 2005, 2009; Fagan et al., 2005; Kovandzic et al., 2009; Zimring et al., 2010), and laws about weapons (Duggan, 2001; Lott, 1998, 2010; Ludwig, 1998; Aneja et al., 2014; Ayres \& Donohue, 2003; Black \& Nagin, 1998; Dezhbakhsh \& Rubin, 2003; Kleck \& Patterson, 1993; Lott \& Mustard, 1997; Moody \& Marvel, 2005).

In these subjects, there exist contradictory results with significant differences in the estimated coefficients. In common among all these works is the difficulty that researchers face in addressing violations of the strict exogeneity hypothesis that the estimation of a regression model imposes. From a scientific point of view, the ideal scenario to overcome these difficulties is a randomized experiment. Although some public policy experiments have been performed (Munnel, 1986; Kling et al., 2007; Ludwig \& Kling, 2007), their use to assess laws is impracticable because a law cannot be applied randomly to groups of individuals. A fundamental principle is that the law must be the same for all. Therefore, in a more realistic vision, there remain few alternatives for empirical researchers of law.

One alternative is the use of exogenous variables that alter the treatment and are capable of separating of the control and treatment groups without the influence of the researcher; i.e., what is called a quasiexperiment is performed. Lee and Lemieux
(2010) argue that causal inferences from Regression Discontinuity Design (RDD) are potentially more credible than those from typical "natural experiment" strategies (e.g., difference-in-differences or instrumental variables) since it provides randomized variation trough the agents' inability to control the assignment variable near the cutoff.

In the empirical analysis of laws, Lee and McCrary (2005) call our attention to the quasi-experiment that occurs with the passage to the age of criminal responsibility, when the punishment faced by an individual is abruptly altered. As individuals near the threshold age (18 years of age), they possess similar characteristics, and it is possible that there exists a discontinuity in criminal recidivism. According to the authors, their methodology makes it possible to overcome the recurring endogeneity problems that are faced when additional data from cities facing increasing crime are obtained because these units tend to respond to the increase in criminality with more severe punishments. In addition, the model makes it possible to isolate the deterrent effects from the traditional combination of incapacitation and deterrence. Using longitudinal information from the State of Florida, where criminal responsibility is reached at the age of 18, the authors estimate a $2 \%$ reduction in criminality for a punishment increase of approximately $230 \%$

A similar situation holds for child labor in Brazil because there is a cutoff age under law. Any form of work is forbidden for children under the age of 14 years old. Above 14 years old, working as a trainee is allowed as long as the activity is not considered unhealthy; such activities are only allowed 
for individuals older than 18 years of age. Assuming that there are no significant differences in the physical and intellectual capacities of individuals with ages close to 14 years and that the only difference between them is the different costs (of expected punishment) to which their employers and parents/guardians are subject for their use as workers, it is possible to conclude that this situation is a quasi-experiment. In this manner, the deterrent effects of the law that prohibits child labor in Brazil can be determined by identifying whether there is a discontinuity in the hours worked per week near the age of 14 years old.

There are only a few studies that evaluate the impacts of such laws, also known as minimum employment ages laws on child labor. Moehling (1999) tests whether minimum age limits for manufacturing employmentenacted trough the last century constrained the occupational choices of children. She uses a triple differences procedure to isolate the effects of the laws from the effects of other forces influencing the demand and supply of child labor. She founds that minimum age limits had negligible effect on the occupation choices of children at the turn of the century and conclude that these restrictions contributed little to the long run decline in child labor. Edmonds and Shrestha (2012) use a crosscountry micro-data to investigate the impact of minimum employment age laws on child labor and schooling. They found no effects of enforcement of such laws in all countries but one. Bharadwaj et al. (2013) assess the effectiveness of the 1986 child labor Indian law change that established 14 as the minimum legal age to work. Surprisingly, their results suggest that such law increased child labor and reduced wages. Using micro- data from Brazilian "Pesquisa Nacional de Amostra por Domicílios" (PNAD), or National Household Sample Survey, Piza and Souza (2016a) found that an increase in the minimum legal age to work without restrictions (i.e. staying at school) in Brazil from 14 to 16 in 1998 more than halved the labor-force participation rates of boys but had no effect on girls. In another study, Piza and Souza (2016b) use cross-sectional data to apply a fuzzy regression discontinuity design to estimate the impact of the ban at different points of individuals' lifecycles (cohorts). Their estimates show that the ban reduced the incidence of boys in paid work activities by 4 percentage points or 27 percent. However, since they were only interested in analyzing the impact of the natural experiment that emerges with the law change, they do not study the impact of such laws on the contemporary child labor participation and volume, which is an effective way to measure their deterrent effect.

Therefore, the aim of this article is to identify the deterrent effects of the law that forbids child labor in Brazil trough the work volume (journeys). For this purpose, this study uses information from the 2013 "Pesquisa Nacional de Amostra por Domicílios" (PNAD), to determine whether there is a discontinuity in the number of weekly hours worked among individuals of approximately 14 years of age. Although it uses alternative methodologies, the paper puts most emphasis on the results obtained for the local average treatment effect (LATE) using the methodology for the choice of bandwidth in regressions with discontinuity proposed by Cattaneo, Calonico and Titiunik (2014). We believe that the article contributes to the literature by providing a more 
robust methodology (based upon a quasiexperiment) for assessing the deterrent effects of laws compared with traditional methods. In addition, it uses a large sample that covers the whole national territory of an underdeveloped country, which is known for the difficulty of applying its laws because of its hampered surveillance capacity either due to the inefficiency of the justice systems or to its large territory. To address these difficulties, different estimations are performed for the urban and rural areas of the country.

The article is organized as follows: the following section presents more details regarding child labor legislation in Brazil, discussing its history and defining its current features. The third section details the strategy of identification used. The fourth section presents the results. At the end of the article, some final considerations are presented.

\section{BRAZILIAN CHILD LABOR LAW}

Brazilian legislation adopts a receptive attitude toward international norms, especially when it addresses issues regarding human rights. The 1988 Federal Constitution (FC), the supreme and fundamental law of Brazil, defines the basic precepts with which all other rules (laws, statutes, codes, etc.) must be in accordance. Regarding the protection of children and adolescents, the implementation of the FC represented an unprecedented rupture in the reality of addressing underage children: children and adolescents as subjects of law, not mere objects of intervention.

The Convention on the Rights of the Child, which was adopted by the United Nations' General Assembly in 1989, recognized the need for special care and assistance to families, the fundamental group of society, for them to fully assume responsibilities in the community, thus ensuring the growth and well-being of their members, and most importantly, children. The document was ratified by 193 countries in 1990 in Brazil. The Convention demands, with the force of international law, that the signing countries make their legislation conform to these rules and commit themselves to not violating them. Consequently, the Brazilian legislature was guided to establish the basis of the Doctrine by defining the basis of the Integral Protection Doctrine, contemplated in FC article 227, which proclaims a set of rights, of an individual nature, that are diffuse, collective, economic, social and cultural, and that recognizes children and adolescents are subjects of rights and, given their vulnerability, need special care and protection.

In accordance with the $\mathrm{FC}$, the "Estatuto da Criança e do Adolescente" (ECA), Statute for Children and Adolescents, was established by Law n. 8.609 / 1990. The ECA represents a synthesis of encodings that specify and deepen the juridical issues within the sphere of the social and legal treatment for minors. More specifically, it provides for the integral protection of children and adolescents, even internalizing a number of international standards.

According to article 2 of the ECA, in Brazil, the definition of a child is all individuals between the ages of zero and twelve complete years of age, and an adolescent is an individual between the ages twelve and eighteen years old. To such individuals, the ECA ensures as a priority all the fundamental rights inherent to the human person, with fitting punishments under the law in response to any attempted or actual 
violation of these rights.

Concerning the object of study of this paper, in what situation are the rights of children and adolescent infringed? To answer this question, we must identify a definition of child labor or have knowledge of which forms must be abolished, although there are divergences regarding a definitive concept. According to the International Labor Organization (ILO), not all the work performed by children and adolescents is classified as child labor, and not all forms of work performed by children must be eliminated. In general, activities that give childrenskillsand experience, thus preparing them to become productive individuals in society, are considered beneficial.

The main reasons to restrain child labor are linked to the damaging effects on performance and school attendance, with school dropout being an aggravating factor. Such consequences are generally triggered by physical and psychological fatigue. Because poverty is always noted as one of the main determinants of child labor, the deterrent to formal education reinforces the condition of social vulnerability because human capital is perhaps the only factor capable of breaking this paradigm - known as the intergenerational factor of poverty. In addition, child labor involves violation of legislation that specifies the minimum age admitted for work.

Convention n. 138 of the ILO, which has been in force since 1976 and was ratified by Brazil in 2002, adopted several proposals regarding the minimum age for obtaining employment. In article 2, it establishes that each signing country will specify the minimum age for admission to work. In this sense, the ECA in article 60, in consonance with the FC in article 7, XXXIII, defines the minimum age to work as 16 years old, except in the case of apprentices, who can start at the age of 14 .

Although Brazilian legislation protects and prohibits the employment of children younger than 16 years of age, except for trainees from the age of 14 years old, the exploitation of child labor is not classified as a crime but as rather an administrative offence, which certainly limits the law's deterrent capabilities. There are no punishment mechanisms delimited for the practice, leaving only some forms of coercion and mild supervision, both in the general legislation and in special ones. The main reason for this situation is that, with the exception of the punishments foreseen for companies that use child labor, the punishments applied to parents/guardians end up harming the children, i.e., the victims. Payment of fines reduces the family income, and it is thus difficult to apply fines in cases in which child labor is precisely used to complement a family income that is insufficient for the family's subsistence.

The Decree-law n. 5.452 of 1943 that approved the Consolidation of Labor Laws (LLC) devotes a chapter to the norms of the protection of minors who work. In consonance with the FC, the LLC specifies, according to article 404, that the jobs of minors cannot be performed in environments that hamper her physical or emotional development or formation or her morality. When such a situation is found or confirmed, article 407 grants the competent authorities the ability to oblige the minor to abandon the job, allowing the company to provide all the facilities to change the functions. If that requirement is not complied with, termination of the contract 
can be considered. The person responsible for the minor also possesses the prerogative of pleading for contract termination if he considers the work performed to be harmful. In the case of apprentices, article 424 confers on the parents/guardians the obligation of removing them from jobs that diminish their time for studying or necessary rest, whereas employers must guarantee a suitable environment.

According to article 435, offending companies are subjected to fines, the value of each equal to one regional minimum wage "applied as many times as there are underage employees in violation of the law - being able, yet, the sum of the fines exceeding five times the minimum wage, except in the case of recidivism, in which case that total may be increased to double the fine."

Although child labor is not classified as criminal conduct, its practice may be framed as a crime in cases of ill treatment or reduction to a condition analogous to slavery, as provided for in the penal code. The first case, set in article 136, highlights exposure to dangerous persons in authority, custody or supervision, among other purposes, being subjected to excessive or inappropriate work with detention from two months to a year if the work results in injury of a serious nature and from four to twelve years if the work results in death; the sentence is increased by one-third when a violation is committed against children under 14 years of age.

The second aspect, discussed in article 149, refers to submitting the victim to degrading work conditions, forced labor or exhaustive working hours; this is punishable with imprisonment from two to eight years and a fine, in addition to the penalty corresponding to violence. The term of imprisonment is increased by half if the crime was committed against a child or adolescent.

In addition, the ECA provides a set of administrative infractions with corresponding punishments. Article 249 states that noncompliance, fraudulent or with intent, with the duties of the parents or guardians (guardianship or custody) generates an offense with a fine of three to twenty times the minimum wage, applying double the amount for repeat offenders. Repeat offenses can lead to the maximum punishment, loss of custody of the child or adolescent, another form of punishment that can harm the child or adolescent. Excluding cases in which ill treatment or/and slave work exploitation occurs, the legislature and justice system face a dilemma in the application of punishment because the forms of punishment stipulated in the legislation also punish the victim. This generates a certain skepticism regarding the capacity of the law that forbids child labor to generate a deterrent effect. In addition, situations that are not foreseen in the penal code are not supervised by the police. For the effect of supervision of child labor and protection of teenage workers, the Normative Instruction of the Secretary of Work Inspection n. 102 of 2013 was published, according to the principles, rules and limits specified in the FC and in the ECA. In this document, annual supervision planning is defined, and activities intended to combat child labor are placed under the responsibility of the "Superintendência Regional do Trabalho e Emprego" (SRTE), Regional Superintendence of Work and Employment, working articulately together with the organizations and entities that 
compose the network of children and adolescent5 protection, that is to say, institutions with very low coercive power compared with the police.

In addition to these institutional strategies, combating child labor is part of a national plan known as "Plano de Erradicação do Trabalho Infantil" (PETI), Child Labor Eradication Program. This plan started in 1996 was designed to assist children between 7 and 15 years of age from dangerous, unhealthy or degrading forms of labor in specific municipalities. This program uses a combination of conditional cash transfers to poor households and after-school activities. The cash transfer is conditional on children stopping to work, having a minimal school attendance and participating in a range of after-school activities. However, only in 2011 this program was introduced in the "Lei Orgânica da Assistência Social" (LOAS), Organic Law of Social Assistance, article 24-C of the Law n. 12.435/2011. This new Law established that the PETI was nationwide and that children identified as working children should be automatically enrolled in the single social assistance registry (CADÚNICO). This means that these children would be monitored not only by the Justice System, but also by the social assistance network. This was a significant paradigm shift as child labor also became monitored by municipal services, and consequently closer to registered cases.

5 The protection network for children and adolescents is composed of international, federal, state and municipal organizations; employers and workers; civil society; tutelary council; the child and adolescent counci of rights; etc.

\section{IDENTIFICATION STRATEGY}

\subsection{Data}

Until the 1960s, Brazil had only the Demographic Census of the Brazilian Institute of Geography and Statistics (IBGE), which was performed every ten years. Faced with insufficient information about the main aspects of the socioeconomic and demographic growth of Brazil, the National Household Sample Survey (PNAD) was created in 1967 to collect information from inter-censal periods and investigate specific topics not covered by the census.

At the beginning, the survey was administered every quarter. From 1971 onward, it was administered yearly, but this decrease in frequency was offset by an expansion of the scope of its collection. Since 1990, the PNAD has covered all of Brazil, with the exception of the rural areas of six northern states. In these states, issues such as the general characteristics of the population (age, gender, race, etc.), education, work, income, and habitation are approached regularly, and specific subjects are treated sporadically in supplementary research.

To fulfill the purpose of this study, that is, to determine the deterrent effects of Brazilian legislation on the incidence of child labor, the 2013 PNAD was used. The use of this year is justified by the introduction of the Law n. 12.435/2011, which established PETI as a nationwide program part of national strategy of social assistance. Since Brazil is a continental country with more than five thousand municipalities with their own social assistance institutions, it is plausible to suppose that the national policy to eradicate child labor would take effects at least one year and a half later. Besides, to 
delimitate the sample, the analysis of this article concentrates on individuals within the age range between 10 and 18 years of age.

The PNAD uses a probabilistic sample method of homes, adopting a stratified and conglomerate design, with up to three selection stages, which confers it the status of a complex sample. In addition, the study adjusts the weights of the sample units for calibration based on the known population totals. When implementing the calibration, the sample in the interval in question relies on 25,460,964 individuals. However, estimating a non-parametric model with this sample size is not possible on a personal computer. Therefore, to obtain a sample capable of obtaining consistent estimates and that allows the estimation of the proposed econometric model, random sub-samples of 100,000 individuals are extracted.

From the PNAD, information regarding people's age and the number of hours worked weekly is used. For the construction of this variable, information about the year, month and day of birth is compared with the reference date of the PNAD data collection, which is the 29th of September 2013. Starting from there, the age is transformed into a continuous variable. For example, an individual who is 12 years and 6 months old is 12.5 years old. The amount of hours worked represents the amount of hours worked at the date (week) of reference of the research.

Table 1 indicates that, in Brazil, there is a significant number of working children, and thus, many violations of the law that forbids child labor. In 2013, there were approximately 450,000 children who worked and received some type of payment, which can be monetary or in products. The incidence increases with age and is greater in rural areas. In rural areas, the incidence rate is practically double that in urban areas. However, the mere existence of child labor does not necessarily mean that the law is totally inefficient. To reach that conclusion, it is necessary to have a counterfactual scenario in which prohibition does not exist. In other words, what would be the number of children working if the law did not exist?

Table 1: Frequency and relative frequency of child labor by age (complete years) and dwelling area.

\begin{tabular}{lllllll}
\hline & Total & \multicolumn{3}{c}{ Urban } & Rural \\
\hline & Child workers & $\%$ & Child workers & $\%$ & Child workers & $\%$ \\
\hline 10 & 51778 & 1.75 & 14593 & 0.62 & 37185 & 6.32 \\
11 & 74701 & 2.41 & 29801 & 1.18 & 44900 & 7.83 \\
12 & 118120 & 3.61 & 49485 & 1.85 & 68635 & 11.31 \\
13 & 201268 & 5.49 & 90327 & 3.03 & 110941 & 16.15 \\
\hline
\end{tabular}

Source: PNAD 2013. Notes: First column refers to age. The \% column refers to the ratio of child workers and children with the age in the sample. 
In this sense, it is useful to remember Becker's idea (1968) that it is almost impossible for zero-crime equilibria to occur. According to him, society determines what anti-crime policies to implement by performing a cost-benefit analysis. Thus, a situation in which there is no incidence of crime would be conceivable only when the social gains overcome the costs of inhibition; otherwise, it is plausible that the society would not agree to bear such costs. A zero-crime situation is thus unattainable. It is necessary to note that such a paradigm can be applied only to the pecuniary costs of the prevention of violations. However, the core question is what is the liquid value in terms of well-being of a zero-crime society compared with a society where there is a low (therefore positive) level of violations of established rules?

Table 2: Mean weekly working hours in urban and rural areas by age (complete years)

\begin{tabular}{cccc}
\hline Age & Total & Urban & Rural \\
\hline 10 & 0.19 & 0.04 & 0.77 \\
11 & 0.29 & 0.15 & 0.92 \\
12 & 0.58 & 0.32 & 1.71 \\
13 & 0.94 & 0.60 & 2.44 \\
14 & 2.05 & 1.52 & 4.40 \\
15 & 3.31 & 2.85 & 5.43 \\
16 & 6.63 & 6.26 & 8.42 \\
17 & 10.05 & 9.80 & 11.34 \\
\hline
\end{tabular}

Source: PNAD 2013.

If it is considered that all forms of child labor are noxious for society, the negative impacts can be measured in terms of the amount of hours worked. When analyzing the relationship between age and average weekly hours worked, as expected, a positive correlation can be observed. Table 2 provides intuition regarding the results that we wish to demonstrate in this paper: the incidence rate of child labor is greater from the age of 14, which suggests, in turn, that the law reduces the number of hours worked by children. Moreover, Table 2 indicates that the employment of child labor is accentuated when observed separately from the average hours worked weekly in rural areas because the total hours worked by children is at least three times as many as that worked in urban areas. There are several explanations for these differences.

One possible explanation is a market failure that has ultimately generated a culture of child labor in rural areas. There is difficulty in hiring manpower due to restrictions in the offer (generated, for instance, by the working legislation), which increases the price of manpower and consequently reduces the amount of manpower hired. One method of overcoming these obstacles to the expansion of production is to use family manpower outside of labor and criminal law. This situation has remained for generations, which has made child labor considered normal, because it is treated as an initiation into the family business that will guarantee continuity to the family business for another generation, that is, it is a form of recognition by the family and of heritage transmission. In the discussion of the results of the proposed model, we provide some other possible explanations for these differences.

\section{METHODOLOGY}

To attain the objectives of this study, the regression discontinuity design (RDD) method was employed. Within the context of impact assessment, RDD is a non-experimental approach in which 
an individual's attribution as a candidate for treatment, i.e., whether an individual participates in a particular program or treatment, is linked to an exogenous numerical value, defined under an observable variable called the "assignment variable", and has, as a reference, a cutoff point that separates the treatment and control groups.

One of the advantages that makes RDD an attractive approach is the possibility of working with designs of already established programs, thus eliminating the need for the study to be conducted a priori randomly. In the present paper, the relationship is between hours worked weekly (the outcome variable), the continuous age (assignment variable) and the treatment, which in this case is the Brazilian legislation that prohibits any type of work for children younger than 14 years of age.

For the method to be successful, nonbiased estimates and, mainly because it is a non-experimental method that seeks to reproduce a randomized experiment, basic conditions that guarantee the internal validity of the study are needed. In the first place, it is necessary that the assignment variable not be caused or influenced by the treatment. In addition, it must be guaranteed that the cutoff point is exogenous and the attribution to the treatment is based on the score that the candidate obtains (in relation to the cutoff point). Then, it is conceivable to say that the age of any individual is an exogenous variable that is incapable of generating a self-selection bias - in this case, receiving the treatment - i.e., the legal prohibition of working for individuals less than 14 years old is independent of their will. It must be supposed that the discontinuity at the cutoff point is due only to the change of status of the treatment and that the other variables, in the case of being covariates, must exhibit an understated (and continuous) behavior throughout the observations. This is equivalent to saying that there can be no other differences among the individual in the surroundings of this threshold beyond receiving or not receiving this treatment. This assumption would not hold if observed and unobserved characteristics differences could be used to legally forbid an individual about to be 14 years old, and therefore, near this threshold, from working. Intuitively, figure 1 illustrates the relationship between the continuous age of the individuals and the number of hours worked each week.

\section{Figure 1: Local linear polynomial regression of weekly working hours on age}

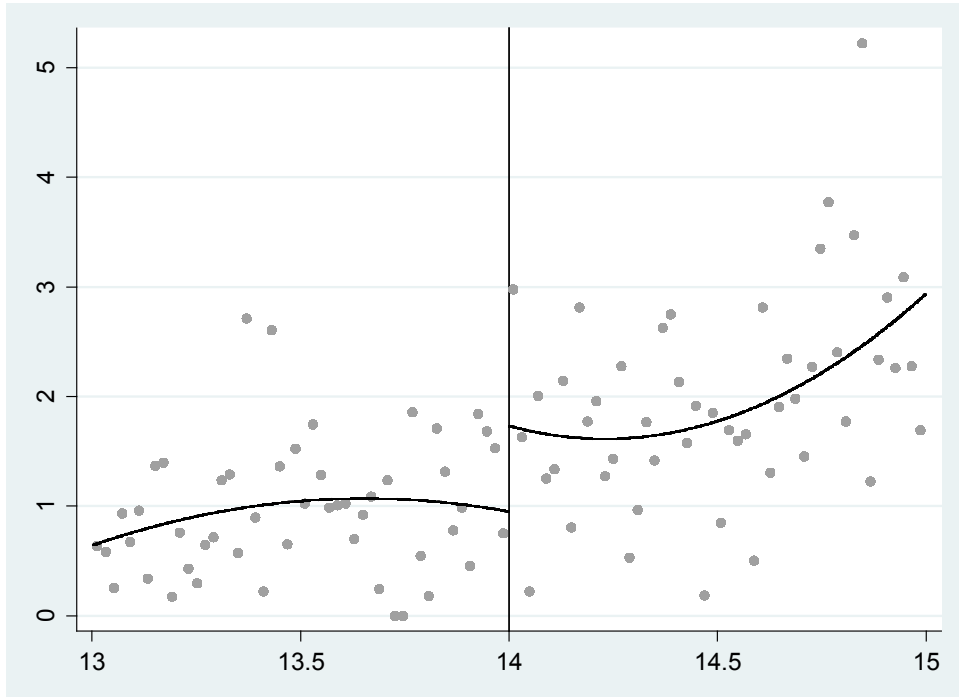

Notes: Local linear polynomial regression with a second-degree polynomial using 100 bins. Cutoff at 14 years old. Sample with individuals from 13 to 15 years old from PNAD 2013.

This figure illustrates a positive correlation, thus indicating that the number of hours worked is quite sensitive to age. In addition, it is possible to observe the occurrence of a jump at the age of 14 years old, that is to say, 
the discontinuity of the cutoff point. Because this observation complies with the premise that the discontinuity is caused solely by the assignment variable, it is feasible to conceive that this break in the continuity, or this abrupt increase in the number of hours worked, is an effect of the law that forbids child labor.

Visual analysis of graphs, such as the plotting of the variable of results against the assignment variable, makes the contrast treatment degree more perceptible, in addition to determining the type of cutoff that the data expresses or observing the behavior in relation to the cutoff point to define the type of discontinuous regression design, fuzzy or sharp. In the first case, which is more common in economic applications, the treatment is partially characterized by discontinuity, in such a manner that it produces a change in the probability of receiving the treatment. This design may be compared to the strategy of a randomized experiment in which some observations of the group of those being treated do not receive intervention, whereas some observations of the control group receive it (these observations are referred to as no shows and crossovers, respectively).

The second type, which is adequate for the data used in this paper, is characterized by complete attribution of each observation to one of the groups; that is, observations where the assignment variable possesses a higher value than the cutoff point will receive the treatment, whereas those that do not exceed this threshold will not receive it. In this case, the probability of receiving the treatment is either 0 or 1 , in contrast with the fuzzy case, in which the probability is a value within this interval. In the sharp design, the treatment attribution variable possesses a deterministic relationship with the variable.

In addition, graphical analysis still provides some evidence regarding the ideal functional form for the relation between the assignment and result variables in the absence of treatment, thus suggesting which of the specifications is the most appropriate for the data. Identifying the correct functional form for the relation between the assignment and the result variables in the absence of treatment is one of the major challenges of regression discontinuity models. The choice of a functional form that does not correspond to the real one will imply a biased estimator of the LATE of the intervention on the cutoff point.

There are two strategies to correctly specify the functional forms of a discontinuous regression. The parametric strategy (or global strategy) uses all the observations of the sample to model the result as a function of the assignment variable and treatment status, thus estimating the average result for observations near the cutoff point. Alternatively, there is the non-parametric strategy (or local strategy) in which the estimate of the treatment effect functions as a local randomization, limiting the analysis to the observations nearest to the cutoff point; such a neighborhood is commonly called a sample. It is understood that in this neighborhood, it is acceptable to assume a linear functional form. However, the major challenge when implementing the nonparametric approach is the correct choice of the bandwidth. Once chosen, the next step is to estimate the linear model with the observations contained in that interval on both sides of the cutoff point.

As is already known by empirical researchers, 
the parametric approach seeks to choose the correct model for a certain database, whereas the non-parametric approach seeks to choose the correct data for a given model. Nonetheless, the choice of one of the approaches necessarily implies a tradeoff between bias and precision: once the global strategy uses all the observations, the sample confers a precision gain, therefore increasing the chance of bias, given the difficulty of correctly specifying the functional form. The opposite holds for the non-parametric method.

According to Imbens and Lemiux (2007), in practice, for estimating the LATE of an RDD, it is customary to apply a non-parametric methodology. Calonico, Cattaneo and Titiunik (2014) note that the local polynomial regression method is appropriate, given the "local" structure and nature of an RDD, because this method provides great performance within the proximity of a limit. In addition, it attributes certain rigidness to the treatment of the parametric method, in terms of its functional form, being susceptible to the bias of, for example, considering a non-linearity of the model as a discontinuity. The non-parametric approach allows that flexibility once it reaches a functional form that better adjusts itself to the data.

Framing the paper discussion in the RDD language, the potential impact of the law that forbids child labor in force in Brazil acts as a treatment and should be evaluated. The treatment group is composed of children and adolescents less than 14 years old, whereas their counterfactual is composed of adolescents who are already 14 years old. The triage between those treated and control is a deterministic function of the assignment variable (continuous) of age.

\section{RESULTS}

Although a regression with discontinuity is very attractive, it is quite challenging because it is necessary to deeply assess the robustness of its estimates. Therefore, to guarantee greater robustness of the proposed methodology, several strategies have been adopted. According to what was discussed before, our basic model has a sub-sample of a reasonable size: 100,000 observations. ${ }^{6}$ To take advantage of the flexibility provided by the non-parametric model chosen, four different functional forms are estimated to adjust the data to a polynomial that can be up to the second order. In addition, the estimations are applied using different samples, that is to say, considering symmetrical age intervals of 3, 6 and 9 months.

Alternative methodologies for obtaining the bandwidth are also used, that is, the neighborhood in which the observations are considered in the estimation of the functional form - being that the greatest challenge of the implementation of a model with a non-parametric approach. For such a purpose, this estimation is data driven; that is, starting from the data (input) and operating through an algorithm, the result is reached (output) without any interference based upon "empirical intuitions". We use the following three different methods for bandwidth selection: Cattaneo, Calonico and Titiunik's (2014) method, hereafter CCT; Imbens and Kalyanaraman's (2012) method, hereafter IK; and finally, Ludwig and Miller's method (2007), hereafter CV?.

Besides, we check for different cutoffs estimating models from the age of 13 to ${ }^{6}$ Since there is not a consensus about the weights use (Solon et al., 2015), in the appendix, we report the results of models without weights. The results keep the signal and present lower magnitude, but the smaller sample implies on lower statistical significance of coefficients. The IK and CV results are showed in the appendix. 
16 years old in half year intervals. Results presented in the table A.3. shows that coefficients are not significant in most of models even when the age of 16 is considered. It should be remembered that after 16 years old the Brazilian Law allows to work without any time or school attendance restrictions. These results give us the conviction that the optimal cutoff to assess the impacts of Brazilian child labor Law is 14 years old. Considering that, table 3 presents the results of the $\beta_{s}^{\prime}$ coefficients that represent the "jump" that occurs in the average of weekly hours worked when the individual becomes 14 years old under different intervals of individuals at a certain age.

The interpretation of the results concentrates on \pm 9 -month samples, this is, theobservations for which the ages are between 13 years and
3 months of age and 14 years and 9 months of age, because it uses the greatest sample ( $h=0.210$ ) with 2002 observations on the left side of the cut-off and 2135 observations on the right side, a sufficiently large sample to guarantee very small bias in the results, and sufficiently near the age of 14 to allow the control of possible differences in the characteristics of the individuals. In this manner, it can be inferred that the federal law forbidding any type of work for children and adolescents below the age of 14 inhibits an average of 1.92 working hours per week, which means an approximately $88 \%$ reduction in the working hours, since there is a change from 0.24 before the cut-off to 2.16 after the cut-off. In other words, it can be said that the law fulfills its objective of deterring work by children and adolescents ${ }^{8}$.

${ }^{3}$ Compared with the results obtained by other methods of selecting the bandwidth, there is not too much divergence relative to the IK method; however, in the CV method, there is a tendency to overestimate the results, which makes interpretation infeasible even though the results are formally statistically significant.

Table 3: LATE of child labor law in weekly working hours

\begin{tabular}{|l|l|c|c|c|}
\hline & & \pm 9 months & \pm 6 months & \pm 3 months \\
\hline Polynomial order & $\mathrm{n}$ & 15456 & 10410 & 5185 \\
\hline & & & & \\
& $\beta$ & $1.6549^{* * *}$ & $1.7685^{* * *}$ & $1.7179^{* *}$ \\
& & $(0.6286)$ & $(0.6758)$ & $(0.7127)$ \\
& \multirow{2}{*}{$\beta$} & $1.9263^{* * *}$ & $1.9242^{* * *}$ & $1.5792^{* *}$ \\
& & $(0.6519)$ & $(0.6563)$ & $(0.8150)$ \\
\hline
\end{tabular}

Notes: entries are the LATE obtained using the CCT method for bandwidth selection. The time intervals indicated at the top of columns refer to the sample of age intervals below and above the cutoff of 14 years old used. The first column indicates the polynomial order of the estimated models. The second line lists the sample count. The standard errors quoted in brackets are clustered by Brazilian state. ${ }^{* * *} p<0.01,{ }^{* *} p<0.05,{ }^{*} p<0.1$. 
For the analysis of individuals residing in urban areas, we again believe it better to use the largest sample, having as a result a local average treatment effect of 1.26 hours of work per week. Similar results are found when other methods are applied for the selection of the bandwidth. Although it seems that the impact of the law is lower in urban areas than in the country as a whole, it is worth remembering that the number of hours worked in urban areas is significantly less than the average for the whole population. The law reduces $82 \%$ working hours in urban areas. Thus, the impact of the law is also high in urban areas. This result was somewhat expected because monitoring in urban areas is easier; consequently, there is a greater likelihood of punishment, specially of companies.

Table 4: LATE of the child labor law in weekly working hours in urban areas

\begin{tabular}{|c|c|c|c|c|}
\hline & & \pm 9 months & \pm 6 months & \pm 3 months \\
\hline Polynomial order & $n$ & 12.488 & 10.585 & 5.169 \\
\hline 1 & $\beta$ & $0.9645^{*}$ & $2.593^{* * *}$ & $2.6861^{* * *}$ \\
\hline & & (0.53079) & (0.75635) & $(0.8324)$ \\
\hline 2 & $\beta$ & $1.2625^{* *}$ & $2.4603^{* * *}$ & $2.5367^{* *}$ \\
\hline & & (0.60107) & (0.77485) & (1.0193) \\
\hline
\end{tabular}

Notes: entries are the LATE obtained using the CCT method for bandwidth selection. The time intervals indicated at the top of columns refer to the sample of age intervals below and above the cutoff of 14 years old used. The first column indicates the polynomial order of the estimated models. The second line lists the sample count. The standard errors quoted in brackets are clustered by Brazilian state. ${ }^{* * *} p<0.01,{ }^{* *} p<0.05,{ }^{*} p<0.1$.

In contrast, when considering individuals who reside in rural areas, the estimated models yield results that are not statistically significant. Therefore, it is understood that the results of the analysis of individuals who reside in rural areas are not conclusive.

Certainly, inspection is more complicated in rural areas because of the large distances involved, and hence, the significantly greater monitoring costs. However, other factors contribute to this result. The fact that child labor is ubiquitous in family agriculture is one of these factors. In this case, it is not possible to punish companies, leaving only punishment for the parents/ guardians. However, parents are the individuals responsible for the sustenance of their families, and a punishment could generate a higher cost for the child than the evil caused by child labor. This dilemma that the justice system faces, according to what was discussed in section 2, is most likely the major cause of impunity for violations of the law that prohibits child labor in Brazil. However, as has been previously discussed, the law is only one element considered by the parents/guardians and businesses in the hiring of illegal workers. 
Table 5: LATE of child labor law in weekly working hours in rural areas

\begin{tabular}{|l|c|c|c|c|}
\hline Polynomial order & & \pm 9 months & \pm 6 months & \pm 3 months \\
\hline \multirow{4}{*}{1} & $\mathrm{n}$ & 2804 & 1907 & 986 \\
& & & & \\
& $\beta$ & 0.2017 & 0.4789 & 4.3233 \\
& & $(1.6795)$ & $(1.8807)$ & $(3.4980)$ \\
& $\beta$ & 1.1795 & 2.8820 & 5.1928 \\
& & $(1.7718)$ & $(3.0569)$ & $(3.9352)$ \\
\hline
\end{tabular}

Notes: entries are the LATE obtained using the CCT method for bandwidth selection. The time intervals indicated at the top of columns refer to the sample of age intervals below and above the cutoff of 14 years old used. The first column indicates the polynomial order of the estimated models. The second line lists the sample count. The standard errors quoted in brackets are clustered by Brazilian state. ${ }^{* * *} p<0.01,{ }^{* *} p<0.05,{ }^{*} p<0.1$.

Beyond juridical and economic factors, which are characteristic of transition economies, it cannot be ignored that there are social factors and cultural norms that confer to the exploitation of child labor a condition of acceptability in the eyes of society. Within this perspective, the use of child labor is characterized in rural jobs, primarily agriculture - where in many cases, money is not a determining factor - in terms of the cultural aspects of production and moral values in family agriculture in which early work commonly confers a status of dignity.

\section{FINAL CONSIDERATIONS}

Following the order proposed by Donohue (2015), quasi-experiments are superior to other econometric models, such as panel data or cross-sectional data, and superior to time series. This order of course holds only when quasi-experiments are correctly applied, as highlighted by the author. In this sense, this paper presents an alternative and somewhat innovative method for the assessment of laws, namely, regression with discontinuity. The proposed method enables estimation of the average treatment effects without the recurring worry of violating the strict exogeneity hypothesis that common to other methods, but it naturally has some limitations.

First, it does not allow dissociating the effects of the change in the probability of punishment and the severity of the punishment because the passage to the age of 14 years old alters both. Second, the proposed method estimates an average treatment effect by comparing only the individuals around this cutoff point. Therefore, its results cannot be extrapolated to the rest of the sample. However, the effect of the law on the quantity of weekly worked hours can be different for children who are 10 or 11 years old than for those who are near the cutoff point (14 years of age).

Despite these limitations, the results obtained provide interesting contributions to the debate regarding empirical assessments of laws and policies aimed at reducing child labor. This paper indicates that the eradication of child labor through 
prohibition is not effective. Although there is an average reduction of $88 \%$ in hours of work per week, there still are approximately 450 thousand children working in Brazil who are thus violating the law, mostly in rural areas. As it is well documented by several studies over time, child labor generates reduced opportunities and lower income in adulthood (Emerson \& Souza, 2011; Ilahi et al., 2000; Kassouf \& Santos, 2010;). Thus, it is an important factor to explain the high level of income inequality observed among adult Brazilians.

The dilemmas faced by the justice system to punish this crime certainly weaken the effects of this law. Moreover, the weakness of this prohibition is more evident when considering rural areas, where supervision is weaker, and the incentives for child labor are different from those in urban areas.

In urban areas there is a plentiful supply of workers and a demand for more specialized and qualified labor skills, something that children are unable to achieve due to the short time at school, that discourage the children hiring. While in rural areas, cultural factors, difficulties accessing schools ${ }^{9}$, and a short supply of manpower, among other factors, help explain the ineffectiveness of the law that prohibits child labor in these areas.

After all, the law is only one factor considered by agents in their decision-making. The eradication of child labor requires complementary strategies in addition to prohibition.

Beyond repression and punishments, primarily of enterprises, the Brazilian

Becker et al. (2014) do a deeper discussion of this issue and show empirical evidences that the difference in the school access between urban and rural areas it is an important factor that explain the highest incidence of child labor in rural areas in Brazil. government has taken action with advertising campaigns informing the population that child labor is forbidden and has a cash transfer program known as PETI, the Program for the Elimination of Child Labor. The program consists of provision of a monthly income to families who have received an admonishment due to their use of child labor. This program, which was assessed in Machado and Oliveira (2014), is partially motivated by the mistaken conclusion that child labor in Brazil is strongly associated with insufficient family income. The authors demonstrate that the program is not capable of reducing the supply of child labor in one of the Brazilian states, Rio Grande do Sul. However, the program proved to be capable of increasing school attendance.

Certainly, this subject demands more research to assess not only the public policies adopted but also the efficiency of the agents responsible for application of the law. In this sense, research that disaggregates individuals by state would allow us to assess the performance of the local justice systems in reducing child labor.

\section{REFERENCES}

Abadie, A., \& Gardeazabal, J. (2003). The Economic Costs of Conflict: A Case Study of the Basque Country. American Economic Review, 93, 113-132.

Aneja, A., Donohue, J., \& Zhang, A. (2011). The Impact of Right-to-Carry Laws and the NRC Report: Lessons for the Empirical Evaluation of Law and Policy. American Law and Economics Review, 13, 1-68.

Ayres, I., \& Donohue, J. (2003). Shooting Down the More Guns, Less Crime Hypothesis. Stanford Law Review, 55, 1193-1312. 
Becker, G. (1968). Crime and Punishment: An Economic Approach. Journal of Political Economy, 76(2), 169-217.

Becker, K. L., Costa, J.S., \& Pavão, A. R. (2014). Determinantes do Trabalho Infantil no Brasil Rural. Revista de Economia Agrícola, 61(1), 49-61.

Berk, R. (2005). New Claims about Executions and General Deterrence: Déjà Vu All Over Again? Journal of Empirical Legal Studies, 2, 303-330.

Bharadwaj, P., Lakdawala, L. K., \& Li, N. (2013). Perverse Consequences of Well-Intentioned Regulation: Evidence from India's Child Labor Ban. NBER Working Paper, n. 19602.

Black, D., \& Nagin, D. (1998). Do 'Right to Carry' Laws Reduce Violent Crime? Journal of Legal Studies, 27, 209-q19.

Calonico, S., Cattaneo, M., \& Titiunik, R. (2014). Robust data-driven inference in the regression-discontinuity design. The Stata Journal, 14(4), 909-946.

Cohen-Cole, E., Durlauf, S., Fagan, J., \& Nagin, D. (2009). Model Uncertainty and the Deterrent Effects of Capital Punishment. American Law and Economics Review, 11, 335-369.

Dezhbakhsh, H.; Rubin, P. H., \& Shepherd, J.M. (2003). Does Capital Punishment have a Deterrent Effect? New Evidence from Postmoratorium Panel Data. American Law and Economic Review, 5, 344-376.

Donohue, J. J. (2015). Empirical Evaluation of Law: The Dream and the Nightmare. American Law and Economics Review, 17(2), 330-360.

Donohue, J., \& Wolfers, J. (2005). Uses and Abuses of Empirical Evidence in the Death Penalty Debate. Stanford Law Review, 58, 791-846.

Donohue, J., \& Wolfers, J. (2009). Estimating the Impact of the Death Penalty on Murder. American Law and Economics Review, 11, 249-309.

Duggan, M. (2001). More gun, more crime. Journal of Political Economy, 109, 1086-1114.
Edmonds, E., \& Shresta, M. (2012). The Impact of Minimum Age of Employment Regulation on Child Labor and Schooling. IZA Journal of Labor Policy, 1-14.

Emerson, P. M., \& Souza, A. P. (2011). Is Child Labor Harmful? The Impact of Working Earlier in Life on Adult Earnings. Economic Development and Cultural Change, 59(2), 345-385.

Fagan, J. (2006). Death and Deterrence Redux: Science, Law and Causal Reasoning on Capital Punishment. Ohio State Journal of Criminal Law, 4, 255-320.

Fagan, J., Zimring, F., \& Geller, A. (2005). Capital Punishment and Capital Murder: Market Share and the Deter rent Effects of the Death Penalty. Texas Law Review, 84, 1803-1867.

Ilahi, N., Orazem, P., \& Sedlacek, G. (2000). The Implications of Child Labour for Adult Wages, Income and Poverty: Retrospective Evidence from Brazil. The World Bank, mimeo.

Imbens, G., \& Lemieux, T. (2008). Regression discontinuity designs: A guide to practice. Journal of Econometrics, 142(2), 615-635.

Imbens, G., \& Kalyanaraman, K. (2012). Optimal Bandwidth Choice for the Regression Discontinuity Estimator. Review of Economic Studies, 79(3), 933-959.

Iyengar, R. (2008). I'd rather be hanged for a sheep than a lamb: the unintended consequences of threestrikes' laws. NBER Working Paper, n. 13784.

Kassouf, A. L., \& Santos, M. J. (2010). Consequência do trabalho infantil no rendimento futuro do trabalho dos brasileiros: diferenças regionais e de gênero. Available from: http://www.anpec.org.br/ encontro2010/inscricao/arquivos/000-7bfe42d90954e 5040f9bdae429f5le3c.pdf

Kleck, G., \& Patterson, E. B. (1993). The impact of gun control and gun- ownership levels on violence rates. Journal of Quantitative Criminology, 9, 249-287.

Kling, J. R., Liebman, J. B., \& Katz. L.F. (2006). Experimental Analysis of Neighborhood Effects. NBER Working Paper, n. 11577. 
Kovandzic, T. L., Vieraitis, L. M., \& D. Boots, D. (2009). Does the Death Penalty Save Lives? New Evidence from State Panel Data, 1977 to 2006. Criminology and Public Policy, 8, 803-843.

Lee, D. S., \& Lemieux, T. (2010). Regression Discontinuity in Economics. Journal of Economic Literature, 48(2), 281-355.

Lee, D. S., \& Mccrary, J. (2005). Crime, punishment, and myopia. NBER Working Paper, n. 11491.

Lott, J. R., \& Mustard, D. B. (1997). Crime, Deterrence, and Right-to-Carry Concealed Handguns. The Journal of Legal Studies, 26, 1-68.

Lott, J. R. (1998). More guns, less crime. Chicago: The University of Chicago Press.

Lott, J. R. (2000). More guns less crime: Understanding crime and gun control laws (2nd Ed.). Chicago: University of Chicago Press.

Ludwig, J. (1998). Concealed gun-carrying laws and violent crime: evidence from state panel data. International Review of Law and Economics, 18, 239254.

Ludwig, J., \& Miller, D. L. (2007). Does Head Start Improve Children's Life Chances? Evidence from a Regression Discontinuity Design. The Quarterly Journal of Economics, 122(1), 159-208.

Ludwig, J., \& Kling, J. R. (2007). Is Crime Contagious? Journal of Law and Economics, 50, 491-518.

Machado, G. C, \& Oliveira, C. A. (2014). The Effects of Cash Transfers Programs on Child Labor Incidence in Rio Grande do Sul. Economic Analysis of Law Review, 5(1), 99-117.

Marvell, T B., \& Moody, C. E. (2001). The Lethal Effects of Three-Strikes Laws. The Journal of Legal Studies, 30, 89-106.

Moehling, C. M. (1999). State Child Labour Laws and the Decline of Child Labor. Explorations in Economic History, 36, 72-106.

Moody, C. E., \& Marvell, T. B. (2005). Guns and Crime. Southern Economic Journal, 71(4), 720-736.

Shepherd, J. M. (2002). Police, Prosecutors, Criminals, and Determinate Sentencing: The Truth about Truthin-Sentencing Laws. Journal of Law and Economics, 45, 509-33.

Solon, G., Haider, S. J., \& Wooldridge, J. M. (2015). What Are We Weighting For? Journal of Human Resources, 50(2), 301.-316.

Swinnerton, K., \& Rogers, A. (1999). The Economics of Child Labour: Comment. American Economic Review, 89(5), 1382-1385.

Piza, C., \& Souza, A. P. (2016a). The Causal Impacts of Child Labor Law in Brazil: Some Preliminary Findings. The World Bank Economic Review, Paper and Proceedings, forthcoming.

Piza, C., \& Souza, A. P. (2016b). Short- and Long-Term Effects of a Child-Labor Ban. World Bank Policy Research Working Paper, 7796.

Zimring, F. E. (2008). Criminology and its Discontents: The American Society of Criminology 2007 Sutherland Address. Criminology, 46, 255-266.

Zimring, F. E., Fagan, J., \& Johnson, D. T. (2010). Executions, Deterrence, and Homicide: A Tale of Two Cities. Journal of Empirical Legal Studies, 7, 1-29.

Data de submissão: 03/06/2019

Data de Aceite: 04/05/2020

\section{APPENDIX}


Table A.1: LATE of child labor law using IK method for bandwidth selection

\begin{tabular}{|c|c|c|c|c|c|c|c|c|c|c|}
\hline \multirow[t]{2}{*}{ Polynomial } & & \multicolumn{3}{|c|}{ \pm 9 months } & \multicolumn{3}{|c|}{ \pm 6 months } & \multicolumn{3}{|c|}{ \pm 3 months } \\
\hline & & Total & Urban & Rural & Total & Urban & Rural & Total & Urban & Rural \\
\hline \multirow{3}{*}{1} & $\mathrm{n}$ & 19.328 & 15.809 & 3.519 & 12.975 & 10.585 & 2.390 & 6.381 & 5.169 & 1.214 \\
\hline & $\beta$ & $2,2412^{* * *}$ & $2,4067^{* * *}$ & 0,60154 & $2,4665^{* * *}$ & $2,3164^{* * *}$ & 1,3883 & $3,3721^{* * *}$ & $2,7284^{* * *}$ & 1,5178 \\
\hline & & $(0,5439)$ & 0,59102 & $(2,2247)$ & $(0,60241)$ & $(0,61356)$ & $(2,517)$ & $(0,80296)$ & $(0,7992)$ & $(2,5427)$ \\
\hline \multirow[t]{2}{*}{2} & $\beta$ & $2,233^{* * *}$ & $2,3169^{* * *}$ & 0,59497 & $3,3978^{* * *}$ & $2,4579^{* * *}$ & 1,3041 & $4,2355^{* * *}$ & $2,6919^{* *}$ & 29,508 \\
\hline & & $(0,55051)$ & $(0,55765)$ & 2,2085 & $(0,87799)$ & $(0,8594)$ & $(2,9755)$ & $(1,1072)$ & $(1,1896)$ & $(22,314)$ \\
\hline
\end{tabular}

Notes: entries are the LATE obtained using the IK method for bandwidth selection. The time intervals indicated at the top of columns refer to the sample of age intervals below and above the cutoff of 14 years old used. The first column indicates the polynomial order of the estimated models. The third line lists the sample count. Empty cells mean that the model did not achieved convergence. The standard errors quoted in brackets are clustered by Brazilian state. ${ }^{* * *} p<0.01,{ }^{* *} p<0.05,{ }^{*} p<0.1$.

Table A.2: LATE of child labor law by CV method for bandwidth selection

\begin{tabular}{|c|c|c|c|c|c|c|c|c|c|c|}
\hline \multirow[t]{3}{*}{ Polynomial } & & \multicolumn{3}{|c|}{ \pm 9 months } & \multicolumn{3}{|c|}{ \pm 6 months } & \multicolumn{3}{|c|}{ \pm 3 months } \\
\hline & & Total & Urban & Rural & Total & Urban & Rural & Total & Urban & Rural \\
\hline & $\mathrm{n}$ & 19.328 & 15.809 & 3.519 & 12.975 & 10.585 & 2.390 & 6.381 & 5.169 & 1.214 \\
\hline 1 & $\beta$ & $3,526^{* * *}$ & $3,5575^{* * *}$ & 1,9649 & $3,0479 * * *$ & $2,6516^{* * *}$ & 1,264 & $2,9382^{* * *}$ & $2,4937^{* * *}$ & 0,6015 \\
\hline & & $(0,83425)$ & $(1,0981)$ & $(3,1313)$ & $(0,73365)$ & $(0,88579)$ & $(3,6233)$ & $(0,70207)$ & $(0,7957)$ & $(2,172)$ \\
\hline 2 & $\beta$ & $2,2532^{* * *}$ & $2,6076^{* * *}$ & 0,677 & $3,1652^{* * *}$ & $2,6754^{* * *}$ & 2,4746 & $3,3508^{* * *}$ & $2,5437^{* * *}$ & 2,2627 \\
\hline & & $(0,55583)$ & $(0,6281)$ & $(1,4135)$ & $(0,78307)$ & $(0,83668)$ & $(3,8182)$ & $(0,82399)$ & 0,76883 & $(4,9424)$ \\
\hline
\end{tabular}

Notes: entries are the LATE obtained using the CV method for bandwidth selection. The time intervals indicated at the top of columns refer to the sample of age intervals below and above the cutoff of 14 years old used. The first column indicates the polynomial order of the estimated models. The third line lists the sample count. Empty cells means that the model did not achieved convergence. The standard errors quoted in brackets are clustered by Brazilian state. ${ }^{* * *} p<0.01,{ }^{* *} p<0.05,{ }^{*} p<0.1$. 
Table A.3: Weekly working hours changes under different cutoff ages

\begin{tabular}{|l|l|c|c|c|c|c|c|}
\hline & & 13 years & 13.5 years & 14.5 years & 15 years & 15,5 years & 16 years \\
\hline Polynomial order & $\mathrm{n}$ & 14999 & 15429 & 14690 & 14630 & 14465 & 15050 \\
$\mathbf{1}$ & $\beta$ & -0.2556 & $0.7902^{*}$ & -0.0239 & -0.2085 & -0.4265 & $2.0967^{* *}$ \\
$\mathbf{2}$ & & $(0.2959)$ & $(0.4333)$ & $(0.5469)$ & $(0.7270)$ & $(0.5999)$ & $(1.0366)$ \\
& \multirow{3}{*}{$\beta$} & -0.1448 & $(0.8376)$ & -0.1291 & -0.1123 & 0.4222 & 2.2991 \\
& & $(0.3820)$ & 0.4586 & $(0.6061)$ & $(0.7798)$ & $(0.8355)$ & $(1.4872)$ \\
\hline
\end{tabular}

Notes: entries are the LATE obtained using the CCT method for bandwidth selection and a time interval of 9 months. The age indicated at the top of columns refer to cutoffs. The first column indicates the polynomial order of the estimated models. The second line lists the sample count. The standard errors quoted in brackets are clustered by Brazilian state. ${ }^{* * *} p<0.01,{ }^{* *}$ $p<0.05,{ }^{*} p<0.1$.

Table A.4: LATE of child labor law in weekly working hours (sample without weights)

\begin{tabular}{|l|l|c|c|c|}
\hline & & \pm 9 months & \pm 6 months & \pm 3 months \\
\hline Polynomial order & $\mathrm{n}$ & 9504 & 6339 & 3166 \\
& $\beta$ & $1.2998^{*}$ & $1.3955^{*}$ & $2.0526^{*}$ \\
2 & & $(0.7228)$ & $(0.7597)$ & $(1.1395)$ \\
& \multirow{3}{*}{$\beta$} & $1.4792^{*}$ & $1.6342^{*}$ & 1.9537 \\
& $\beta$ & $(0.8126)$ & $(0.8725)$ & $(1.2114)$ \\
\hline
\end{tabular}

Notes: entries are the LATE obtained using the CCT method for bandwidth selection. The time intervals indicated at the top of columns refer to the sample of age intervals below and above the cutoff of 14 years old used. The first column indicates the polynomial order of the estimated models. The second line lists the sample count. The standard errors quoted in brackets are clustered by Brazilian state. ${ }^{* * *} p<0.01,{ }^{* *} p<0.05,{ }^{*} p<0.1$. 